\title{
Preliminary Study on The Effect of Medicinal Mushroom Extract and Timolol Maleate on Dexamethasone Induced Ocular Hypertension in Feline's Eye Model
}

\author{
${ }^{1}$ Akinlabi Ghalib Ayoakin, ${ }^{1}$ Igbinigie Vivian Eghosasere, \\ ${ }^{2}$ Akpaja Emmanuel Oluwadare And ${ }^{3}$ Vincent Iyawe
}

\begin{abstract}
Mushrooms are like mannas and their water heal eye diseases. To determine if aqueous mushroom extract has an effect on ocular hypertension, 8 cats with baseline intra ocular pressure (IOP) of $14.94 \pm 0.153 \mathrm{mmHg}$ were used in the first phase of this study. The second phase consisted of 2 groups, the experimental and the control groups. The control consisted of 2 cats (4 eyes) while the experimental consisted of 6 cats (12 eyes). Ocular hypertension was induced in the experimental group with $0.1 \%$ dexamethasone treatment ( 2 drops q.i.d $x$ 1/12) and IOP measurement was done weekly using the Perkins hand held Tonometer. The third phase consisted of oculo hypertensive cat eyes $(25.275 \pm 0.363 \mathrm{mmHg})$, which were further divided into control-1 and experimental group. The control-1 group (4 eyes) was left untreated, while the experimental group was divided into 2 groups, the mushroom treated (4 eyes) and timolol treated ( 4 eyes) for 15 days. Mushroom extract decreasel IOP below baseline level showing a significant $(\mathrm{p}<0.001)$ IOP reduction of $5.24 \%$ better than the control group, while timolol was only $0.85 \%$ better.
\end{abstract}

\section{INTRODUCTION}

Corticosteroids have been proven to induce ocular hypertension and consequently steroid induced glaucoma in humans and animals ${ }^{1,2,3,4}$.

Dexamethasone treatment in human has been shown to result in ocular hypertension and the morphological changes in the trabecular meshwork are similar to those reported in corticosteroid glaucoma

KEYWORDS: Mushroom extract, Timolol maleate, Dexamethasone and ocular hypertension.

Department of ${ }^{1}$ Optometry, Department of ${ }^{2}$ Botany, Department of ${ }^{3}$ Physiology University of Benin, Benin City, Nigeria. and open angle glaucaoma ${ }^{5}$. This result has also been replicated in an animal model especially feline as opposed to the inconsistent finding in rabbits ${ }^{6}$.

Ocular hypertensive agents like beta adrenergic blocker are known for reducing IOP, predominantly by influencing the production of aqueous.

Timilol has been found to be the best of these beta blockers ${ }^{7}$ with mild and transient adverse effect ${ }^{8}$ and a direct neuroprotective effect against retinal damage ${ }^{9}$. It also improves the perfusion of the optic nerve head leading to protective effect on visual function ${ }^{10}$.

Mushrooms are like mannas and their water heal eye diseases ${ }^{11}$. This is the 
background information for this research. There is a vast variety of mushrooms, up to 270 of which have medicinal benefits and many others are poisonous. There are also different kinds of eye diseases.

Some of the neutraceutical mushrooms that are dietary are Maitake (Grifola frondosa), reishi (Ganoderma lucidum) shiitake (Lentinula edodes), cordyceps (cordyceps sinensis), Turkey tail (Trametes vesicolor) and lions mane (Hericium erinaceus). Some up and coming mushrooms that have received a lot of attention in the research community are Agaricus (Agaricus brasilienses).

Oyster mushrooms have been recommended as a natural cholesterol lowering substance within human diet ${ }^{12}$. Kabir and Kimura (1989) showed that Lentinula edodes lowers both blood pressure and free cholesterol in plasma as well as accelerate the accumulation of lipids in the liver by removing them from circulation.

There is a functional relationship between systemic blood pressure and intra ocular pressure ${ }^{14}$. We desired to find out if the blood pressure lowering effect of mushroom can also be applied to intra ocular pressure as a form of healing for the eye.

\section{METHOD}

\section{STUDY POPULATION}

8 adult cats of either sex bought from the local market weighing between $1.3 \quad 2.0 \mathrm{~kg}$, were maintained in the animal house of the Department of Pharmacology for a period of 1 month before the beginning of the experiment, to get them used to laboratory environment. The cats were fed with cereals rich in carbohydrate and protein, fish (smoked) and clean water and attained weight of $1.8 \mathrm{~kg}-2.5 \mathrm{~kg}$ after 4 weeks. Their cages were cleaned daily with brush and clean water and Izal to prevent secondary infection from a dirty environment.

\section{RESEARCH DESIGN}

The research was done in 3 phases which took a total period of 10 weeks. The first one month of getting used to laboratory environment was also used to train the cats to accept tonometry, consequently base line IOP reading was established in the first phase for the colony.

IOP measurement was done with the use of Perkins Hand Held Tonometer before and during all treatments, after cornea anesthetia was obtained with the topical application of fluoroscene strip instilled with lignocane. The measurements were taken 3 times a day at $4 \mathrm{hrs}$ interval.

The establishment of base line IOP led to the second phase of the experiment for the next one month when the sample population was divided into 2 groups, the

\section{a.) Experimental group and \\ b.) Control group}

The Experimental group was treated with $0.1 \%$ dexamethasone (maxidex drops) gutt qid for 4 weeks (4/12) while the control group was not treated with any drug. Their normal IOP was left untampered with. This phase spanned a period of 4 weeks involving steroid instillation and IOP measurements. The attainment of significant ocular hypertension marked the end of the second phase and the beginning of the 3rd phase.

The third phase involved the regrouping of Experimental group into 3 groups;

i.) Control- $1=2$ cats

ii.) Group for mushroom Extract Treatment $=2$ cats

iii.) Group for Timolol Maleate Treatment $=2$ cats

Control 1 group had attained ocular hypertension but was not treated with any drug and left to decrease normally. This served as control for experimental group. 
Group for mushroom treatment was treated with aqueous extract of oyster medicinal mushroom (4g/100ml dose: 1 gutt dly x 2/52)) for a period of 15 days with the corresponding measurement and documentation of intraocular pressure. Group for Timolol treatment was treated with Timolol maleate $0.5 \% 1$ gutt dly for two weeks with the corresponding measurement and documentations of intraocular pressure. Results from the experiment were used for statistical analysis.

- LEAST SIGNIFICANT DIFFERENCE (L.S.D)

- DUNCAN GROUPing (GLM PROCEDURE)

- All animals used procedures were in strict accordance with the University of Benin and ARVO Statement for the Use of Animals in Ophthalmic and Vision Research.

\section{RESULTS}

Base line intra ocular pressure (IOP) was established in the last five days of the first one month, after average IOP of three readings at a time was taken three times a day in each eye of the eight cats. The IOP was $14.94 \mathrm{~mm} \mathrm{Hg}$.
Phase 2 involved the treatment of the experimental group with $0.1 \%$ dexamethazone binocularly for 4 weeks, while the control was left untreated. There was a gradual increase in IOP which attained a significant level $(\mathrm{P}<0.0001)$ at the end of the 3rd week at $23.025 \mathrm{~mm} \mathrm{Hg}$ (range 21- 25 $\mathrm{mmHg})$. By the end of the 4 th week the mean value had further increase to $25.65 \mathrm{mmHg}$. The control group has a mean IOP value of $15.5 \mathrm{~mm} \mathrm{Hg}$ in this same period which was not significantly different from the base line IOP of the population. Fig 1 shows the effect of steroidal treatment on the experimental group compared with control group in the last five days of the 4 th week. The percentage increase in IOP from base line was 63\%

Figures 2,3,4 and 5 show the effect of treatment of the ocular hypertensive eyes with timolol, mushroom extract and control. The intraocular pressure in the untreated group reduced naturally (due to the reversible action of steroid as it wears off). After 15 days it reached a mean value of $18.6 \pm 0.31 \mathrm{mmHg}$. Timolol after two weeks of treatment caused the lowering of IOP to a mean value of $18.4 \pm$ $0.68 \mathrm{mmHg}$. This is $0.85 \%$ better than that of the control but not significantly different. Treatment with mushroom extract for two weeks caused the reduction of the IOP to a

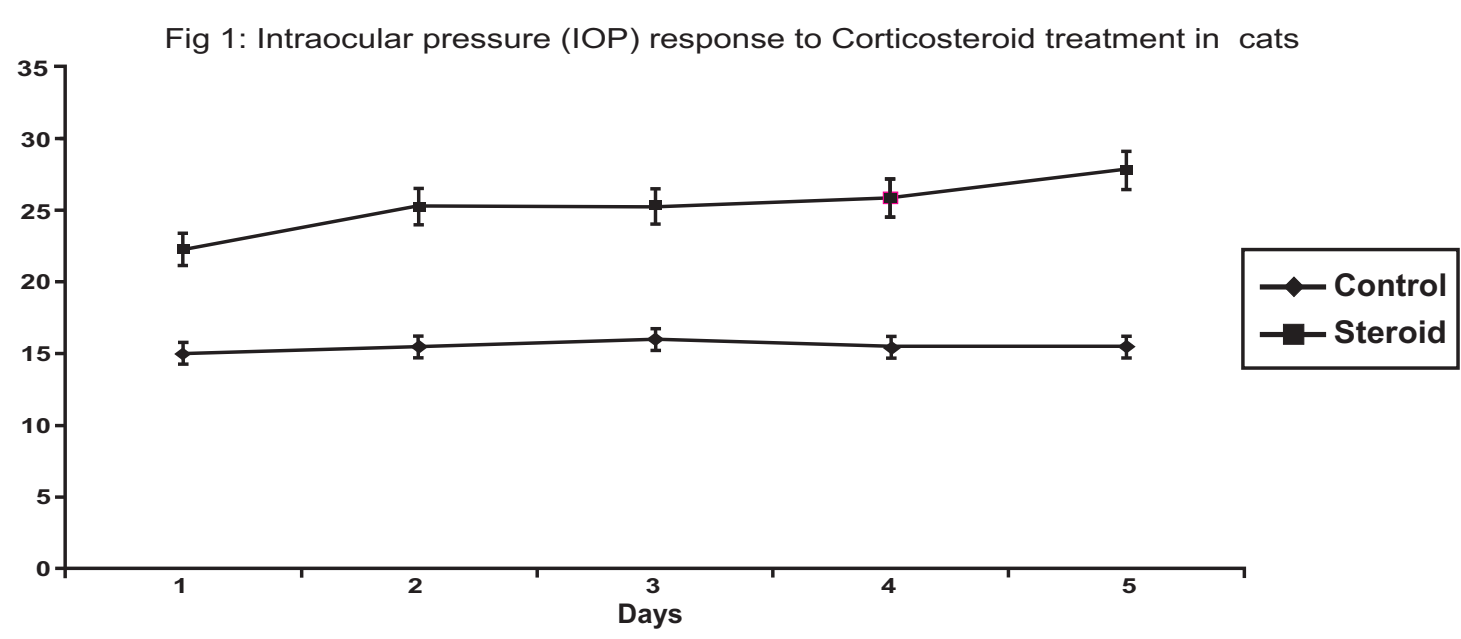

Fig.1: Graphical analysis of the effect of corticosteroid on intraocular pressure of cats used is(last 5 days of phase 2) 
Fig 2: Intraocular pressure (IOP) response to the treatment with mushroom extract, Timolol and Control

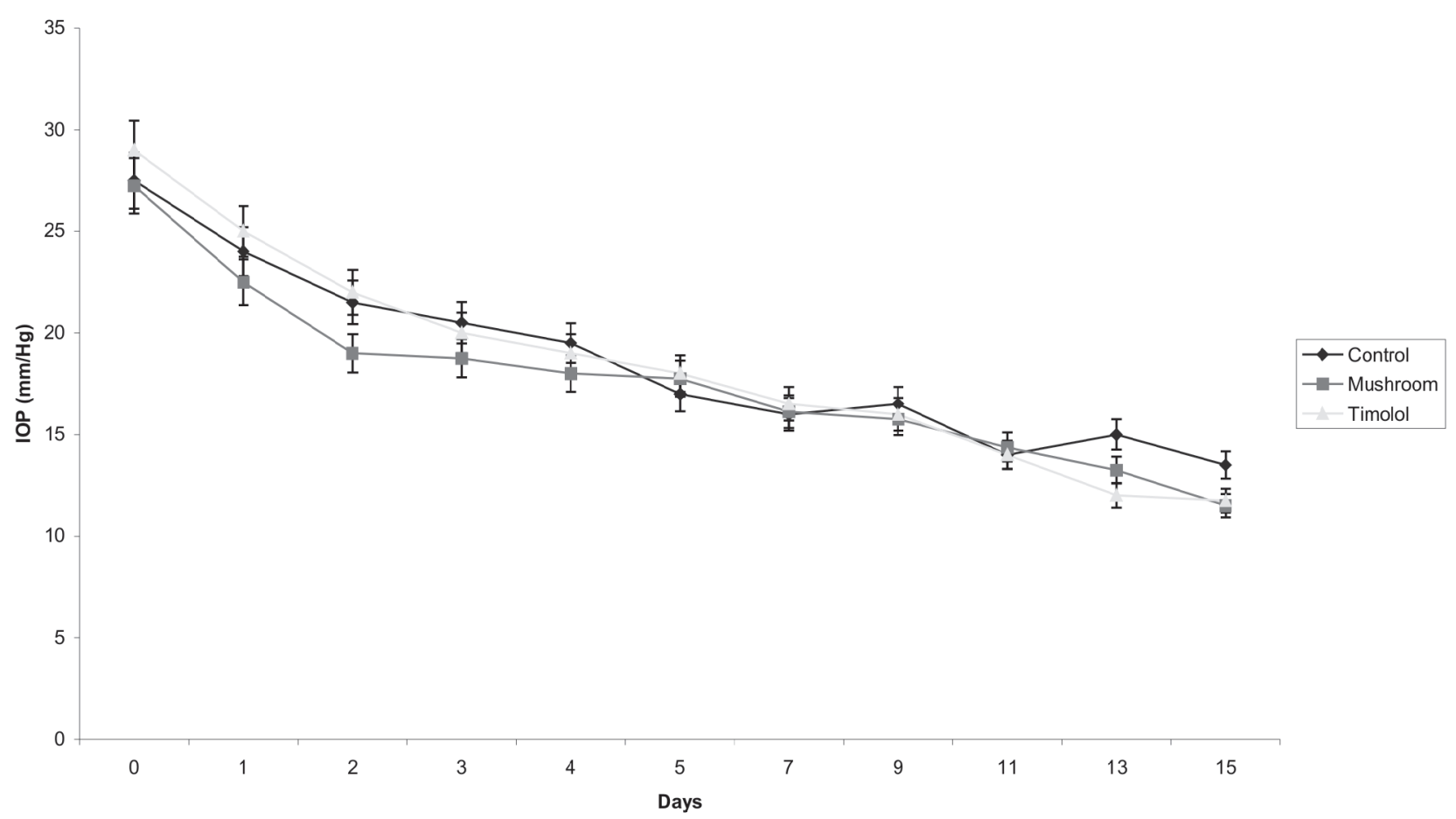

Fig. 2: Graphical analysis comparing the treatment of mushroom (oyster) extract, Timolol and control on corticosteroid induced ocular hypertension in feline models used for this study.

mean value of $17.6 \pm 0.43 \mathrm{mmHg}$. Thus mushroom treatment significantly lowers the IOP of the cats $(\mathrm{p}<.0001)$ when compared with control.

\section{DISCUSSION}

Our findings from this study clearly demonstrate that topical instillation of corticosteroid increases intra ocular pressure in cats contrary to our efforts in the past to do same in rabbits. This further confirms the views of ${ }^{15,16,17,18,6}$. The increase in IOP is steady and continues with the instillation but wears off when the instillation is stopped. This is similar to the occurrence of corticosteroid induced glaucoma in human. Thus we have a good animal model to test glaucoma drugs.

In this study we also demonstrated that timolol a beta blocker and anti glaucoma drug reduced the dexamethasone induce ocular hypertension, but the reduction was not significantly different from that of the control (i.e the reversibility of ocular hypertension when the dexamethasone was stopped). This corroborates the work of ${ }^{19}$ which states that timolol appears to have minimal efficacy in dogs and cats.

The major breakthrough in this study is that topical instillation of aqueous mushroom extract, was found for the first time to significantly reduce IOP in dexamethasone treated cats, when compared with timolo and control. Thus we may have a potential effective anti galucoma drug in the mushroom extract, but there is the need for further investigation.. this may partially confirm the statement of the Prophet Muhammed (peace be on him) that mushrooms are mannas and their water heals eye diseases.

Further investigation is going on to confirm this findings its dosage and mechanism of action. 


\section{References}

1. Linner, E. (1959). Adrenocortical steroids and aqueous humor dynamics. Doc. Ophthlmol; 13:210-23.

2. Goldmann, H. (1962). Cortisone Glacoma. Arch Ophthmol; 68: 621-26.

3. Armaly, M.F. (1963a). Effect of Corticosteroid on Intraocular pressure and fluid dynamics. II. The effect of dexamethasone in the glaucomatous eye, Arch. Ophthamol. 70: 492-9.

4. Beker, B. (1965).Intraocular pressure response to topical corticosteriods. Invest. Ophthalmol 4:198.

5. Clark, A. F. (1995). Dexamethasone induced ocular Hypertension in perfusion cultured human eyes. Invest. Ophthalmol. Vis.Sci. (36) (2): 478-89.

6. Zhan, G. L. Miranda C., and Bito L.Z. (1991). Steroid glaucoma: corticosteroid induced ocular hypertension in cats. Exp. Eye Res. 54 (3): 839-845.

7. Coulangeon. L.M Meunerath M. (1990). Aqueous humor flow measured by Fluorophotometry. A comparative study of the effect of various beta-blocker eyedrops in patients with ocular hypertension Ophtalmologic 4(2): 15661.

8. Nicola, O. Luca R. Andrea B (2004). Effect of Timolol, Dorzolamide and Latanoprost on circadian IOP in glaucoma or Ocular Hypertension. Invest Ophthalmol \&Vis Sci 42: 25662573
9. Goto, W. Ota, T. Monkawa, N. Otori Y, Kawazu K. (2002).Protective effects of Timolol against the neuronal damage induced by glutamate and Ischemic in the rat retina. Brain Res. 958 (1): 109.

10. Montanri, P. Marangoni P. Oldani A . Ratiglia R., Raiteri M., (2001). Color Doppler imaging study in patients with primary open angle glaucoma treated with Timolol $0.5 \%$ and carteolol 2\% Eur J. ophthalmol 11 (3): 240-4.

11. Sahih Al-Bukhari translated by Muhammud Mushin khan (1985) Hadith of The Prophet Mohammed (SAW) vol 7 page 408 Dar Al Arabia\} Beirut Lebanon.

12. Bobek, P. Ozdin, L. and Galbavy, S. (1998). Dose and time dependent hypocholesterolemic effect of oyster mushroom (Pleurotus ostreatus) in rats. Nutrition 14, 282286.

13. Kabir, Y. and Kimura, S. (1989). Dietary mushrooms reduce blood pressure in spontaneously hypentensive rats. Journal of Nutritional Science and Vitaminology 35, 91-94.

14. Bulpitt, C.J. Hode C and Everitt M.G. (1975). Intraocular pressure and systemic blood pressure in the elderly. Br. J. Opthamol 59: 12

15. Tuovinen, E. Liesmaa $\mathrm{M}$ and Esila R. (1966). The influence of corticosteroids on intraocular pressure in rabbits II, The influence of massive subconjunctival doses of dexamethasone and betumethasone. Acta.Ophthalmol. 44: 901-905. 
16. Levene R.Z., Rothberger $M$ and Rosenberg S. (1974). Corticosteroid glaucoma in the rabbit. Am. J. Ophthalmol. 78: 505-510

17. Knepper P.A., Breen M., Weinstein H.G. and Black L.J. (1978). Intraocular pressure and glycosaminoglycan distribution in the rabbit eye: effect of age and dexamethasone. Exp. Eye. Res. 27:567-575.
18. Ticho U., Lahav M., Berkowitz S. and Toffe P. (1979) Ocular changes in rabbits with corticosteroid induced ocular hypertension Br. J. Ophthamol. 63: 646-650.

19. Jaliffa CO, Lacoste FF, Llomoratte DW, Sarmiento MI, Rosentein RE: Dopamine decreases melatonin content in golden hamster retina. J. Pharmacol Exp Ther 2000 Apr; 293 (1) :91-5 